\title{
Niños y adolescentes "gomeros" de la calle. Un caso de Quito
}

\author{
“Gomeros", street children and adolescents. A case in Quito
}

Karina G. Cabrera Cerón

\section{Introducción}

"A través del tiempo la sociedad actual ha ido desconociendo cada vez más las condiciones de la infancia y adolescencia, teniendo esencialmente en la familia el origen de este desconocimiento" (Sánchez Parga, 2009: 7). La familia, considerada como el primer lugar de socialización, donde el niño y adolescente deben encontrar protección, identidad y pertenencia, se encuentra cada vez más frágil y con vínculos y filiaciones cada vez más inciertos siendo la ruptura de estos una de las causas fundamentales para la "callejización" del niño y, por ende, haciéndolo presa fácil de los peligros que este ambiente le ofrece. La pobreza, la falta de cariño, el maltrato físico y psicológico y la poca responsabilidad por fomentar los vínculos familiares, ha obligado a muchos de nuestros niños, niñas $\mathrm{y}$ adolescentes a escapar de sus hogares en busca de otras formas de sociedad.

A este contexto se suma la desvalorización y falta de oportunidades de trabajo debido a que la mayoría de estos chicos son menores de edad, y por ello obligados muchas veces a delinquir o a verse envueltos en actividades que ponen en riesgo su salud física y mental. Y es justamente en esos momentos cuando, al no lograr cubrir necesidades elementales como hambre y sueño, recurren a la inhalación de sustancias volátiles, para calmar la ansiedad que les produce no poder satisfacerlas. Una de las sustancias más conocidas, barata y de fácil adquisición es la goma, más conocida como cemento de contacto, de allí que a este tipo de chicos se los conozca como "gomeros".

De acuerdo con cifras del último Censo de Niños, Niñas y Adolescentes en Situación de Calle, en Quito existen 2.228 menores "callejizados". Las calles son su vivienda, su lugar de juego y recreación, el sitio de sus trabajos ocasionales. Usan la calle como dormitorio, por lo general se les encuentra "fundéandose" y pidiendo comida. La noche aumenta el consumo de dicha sustancia puesto que el frío de las calles de Quito se les vuelve insoportable, más aún si 
este va acompañado del hambre. Los problemas que estos niños y adolescentes afrontan diariamente entre otros son: exclusión social, formas inhumanas de vida, violencia física, desvinculación familiar, maltrato social, fuga social, drogadicción, prostitución infantil, explotación, escasa o ninguna escolaridad, baja autoestima, deterioro de la salud, involucramiento en infracciones, limitada capacidad de plantearse proyectos de vida, falta de afecto, etcétera.

\section{Niños "de" o "en" la calle}

Es importante que hagamos una diferencia de lo que es un niño "de la calle" y un niño "en la calle" para que podamos determinar nuestros sujetos de investigación y que lleguemos a conclusiones más precisas del grupo vulnerado. "Niños de la calle"2 es un término general que se aplica a los niños y las niñas que están en alto riesgo en áreas urbanas, sin tomar en cuenta las diferencias entre ellos. No son todos abandonados y no todos viven en la calle. UNICEF distingue entre dos grupos de niños según la situación de sus familias:

- Los niños y las niñas "en" la calle son el grupo más grande. Trabajan en las calles pero mantienen relaciones cercanas con sus familias. La mayoría (aproximadamente un 75\%) mantienen sus vínculos familiares, y aunque pasan mucho tiempo lejos de ellos, sienten que tienen un hogar.

- Los niños y las niñas "de" la calle (aproximadamente el 25\%) están sin hogar y tienen vínculos familiares rotos debido a la inestabilidad o a la desestructuración en sus familias. En algunos casos han sido abandonados por estas y en otros casos ellos mismos decidieron irse. Comen, duermen, trabajan, hacen amistades, juegan en la calle y no tienen otra alternativa que luchar solos por sus vidas.

Para este grupo de niños y niñas en situación de calle, las drogas juegan un rol importante en sus vidas, en tanto adquieren un sentido social en el grupo de

2 Los niños y niñas en situación de calle son aquellos menores de 18 años que tienen vínculos familiares débiles o inexistentes, que hacen de la calle su hábitat principal y desarrollan en ella estrategias de supervivencia, hecho que los expone a distintos tipos de riesgos (Cfr. Forselledo, A. Niñez en situación de calle. Un modelo de prevención de la farmacodependencia basado en los derechos humanos. Disponible en: http://www.iin.oea.org/forse.pdf.). 
pertenencia y pueden llegar a constituirse en el trabajo que les provee "seguridad". También pueden involucrarse en situaciones como el robo y la prostitución. En este contexto, estos niños quedan atrapados en un ciclo de pobreza y violencia, carentes de atención médica, condiciones sanitarias, supervisión y educación.

\section{Gomeros}

En el argot callejero, cualquier substancia que se utilice para inhalarla y provocar una modificación en la conciencia, en México se conoce como "chemo". El producto de H. B. Fuller es conocido como "Resistol", inclusive los niños hondureños que inhalan este pegamento se les conoce como "resistoleros". ${ }^{3}$ En el Ecuador una de las sustancias para inhalar más usual, económica y de fácil adquisición es la goma, más conocida como cemento de contacto la cual es inhalada desde su recipiente, botellas, fundas plásticas por lo que a la acción de inhalar se le llama "fundear", es una droga de fácil acceso y la de mas bajo costo, que según sus propias palabras les quita el hambre y el frio.

El término "inhalantes" se refiere a una variedad de productos comerciales y de uso doméstico diferentes que pueden ser intencional y abusivamente consumidos mediante la inhalación o "aspiración" (inhalación a través de la boca y nariz) (Forselledo, 2002). Bases solventes narcotizantes contenidas en estas sustancias: el tolueno es un líquido sin color con un fuerte olor dulce. Se usa como solvente y también en la gasolina de la aviación y para la fabricación de otros químicos: perfumes, medicinas, tintes, explosivos y detergentes. El Tolueno figura entre las sustancias más tóxicas y peligrosas y está incluida en la Lista de la Agencia de Protección del Medio Ambiente de los Estados Unidos.

El ciclohexano es un líquido sin color con un olor dulce. Es usado como removedor de pintura, como un solvente para lacas y resinas, y para hacer materiales orgánicos como el nylon. Este compuesto también es altamente tóxico y peligroso para la salud de quien lo inhala. (Forselledo, 2002: 11-13). Dentro de este grupo de sustancias pueden citarse: 1) adhesivos: colas, tolueno, xileno, acetona, benzoles, benzaldehído; 2) aerosoles-sprays-gases: gases propelentes, óxido nitroso; 3 ) cementos plásticos: hexano; 4) solventes de pinturas y relacionados: petróleo, butano, trementina, aguarrás; 5 ) líquidos para limpieza: xileno, benzol, éter de petróleo; 6) anestésicos: éter etílico puro; 7) combustibles: ben- 
cina, naftas; 8) thinner: hidrocarburos halogenados; 9) vasodilatadores: nitrito de amilo, nitrito de butilo, y muchas otras más.

Los efectos de los inhalantes son experimentados por el consumidor al aspirar voluntariamente sus gases, afectando y alterando el funcionamiento del sistema nervioso central (SNC). Específicamente podemos citar los siguientes efectos y daños físicos que causan en los órganos: pérdida de la memoria a corto plazo, coordinación deficiente, distorsiones en la percepción, cuadros severos de dependencia, pérdida de la audición, espasmos en las extremidades, pérdida de lucidez, daño cerebral, en el hígado y riñones, complicaciones por intoxicaciones agudas.

\section{Enfoque teórico}

Para poder explicar este hecho social, de los niños callejizados y que posteriormente serán consumidores de inhalantes, debemos analizar, definitivamente el sistema social y económico actual, y su influencia directa sobre el núcleo familiar que a través de la historia, ha tenido características particulares según el sistema económico en el que se ha desarrollado. Es así como al tomar en cuenta las características de globalización del sistema capitalista, también podemos observar cómo este ha violentado los vínculos más íntimos de la familia y a su vez esta violenta a sus miembros más frágiles. La sociedad de mercado, tiene un solo objetivo, el consumo masivo de bienes y servicios; esto ha provocado que para lograr dicho objetivo se invada violentamente el espacio familiar, entrando por todos los medios (visuales, alternativos, masivos y otros) posibles a su intimidad, "desinstitucionalizandola y rompiendo todos sus vínculos (conyugales, relaciones parentales y de filiación, relaciones de consanguinidad)"

El impacto de la crisis y la gran recesión económica mundial vivida en los últimos años es otra de las causas característica del sistema capitalista, que ha dado paso para que la pobreza se ahonde de forma más radical, y con ella la violencia familiar efecto provocado por la frustración de la falta de dinero y el poder suplir las necesidades básicas y peor aun poder alcanzar las necesidades superiores a estas como lo explica Maslow en su pirámide de necesidades sociales. Cuando las condiciones de subsistencia de una familia en todos sus sentidos se van deteriorando, son remplazadas por la violencia y según lo explica José Sánchez Parga: 
En la familia, más que en ninguna otra institución social, las violencias internas pueden ser más encarnizadas y más destructivas de la personalidad de sus miembros, ya que los liquida como personas pero sobre todo los desestructura en su misma condición familiar: de hijos o hijas, de padres, de cónyuge o de hermanos y esto por las siguientes razones:

$\mathrm{Al}$ ser las relaciones familiares las más estrechas, las de mayor interdependencia y las más afectivas, las agresiones entre ellas acarrean los mayores sufrimientos. En la familia se relacionan íntimamente las dos diferencias más estructurantes de la condición humana: las diferencias sexuales (mujer/hombre) y las diferencias generacionales (adulto/niño). Cuando se fractura la calidad personal de ambas diferencias relacionales, la sexualidad puede convertirse en un objeto o instrumento de violencia, de la misma manera que la diferencia de edad, puede convertir más fácilmente al adulto en agresor de sus hijos.

Las violencias familiares se practican incluso mezcladas o combinadas con la afectividad y sentimientos familiares, lo que lejos de atenuar sus efectos puede volverlos mucho más letales (...). Las violencias familiares no solo gozan de la máxima impunidad, por tener lugar en el enclave más privado de la sociedad, sino que además gozan de una absoluta complicidad y encubrimiento de toda la familia, la cual se rige por el postulado perverso de que "los trapos sucios se levan en casa".

Es decir, que la violencia en su más alto nivel y como mejor ejemplo de la desestructuración social, se encuentra en la familia, y es ésta la causa principal de la fuga de niños y adolecentes que salen a las calles; escapando de dicha violencia sin saber que posiblemente la violencia que les espera es igual o mucho peor que la vivida.

Al llegar a las calles pronto aprende que su sostenimiento en ella depende de su capacidad de desarrollar estrategias para sobrevivir y poco a poco ir supliendo o encontrándose por primera vez con lazos y vínculos de una familia creada por y para las calles, se encuentra entonces con sus pares y forman un grupo donde tiene su propia identidad y que con el convivir diario, a diferencia de lo que la mayoría de personas creen, van naciendo códigos y roles muy marcados dentro de lo que ellos llaman "una familia".

Sin embargo la pobreza extrema que va sufriendo el grupo requiere de estrategias sumamente fuertes para subsistir, o por lo menos evitar en algo la poca o ninguna satisfacción de necesidades básicas según explica Maslow (beber, alimentarse, descansar, vestirse, ambientes cálidos, etc. ), es así que aparece el 
consumo de drogas, en especial y por lo general los inhalantes, ya que como se había mencionado son de fácil obtención y consumo; es decir, el inicio del consumo de inhalantes más que una adicción es una estrategia de sobrevivencia. Al mismo tiempo en que las drogas entran en su mundo y por necesidades económicas el consumo se va delimitando a drogas más baratas pero mucho más mortales como el tiñer, gasolina, cemento de contacto, pvc (pega de tubo), también el ser humano (niños y adolescentes) van llegando al fondo de toda la descomposición social, es decir, llegan al lugar más profundo de toda la pobreza, a una marginalidad completamente invisible.

¿Qué condiciones de vida y forma de sociedad constituyen? Y más aún, ¿existe tal organización?, ¿estos grupos vulnerables se unen para plantearse de cierta forma una estructura? La respuesta es, según nuestra investigación, que los niños y adolescentes progresivamente se encuentran en la calle por motivos de trabajo o descuido del adulto; que poco a poco se van integrando a ella para pasar de ser "niños en la calle" a niños "de la calle" y sus vínculos y aprendizajes se generan en este lugar. Para explicar esto podemos hacer referencia al trabajo de Alfredo Moffat:

Si analizamos las características de personalidad que tienen, están definidas por: 1) la no historicidad (no memoria y no proyecto de vida) lo que llamamos psiquismo acrónico (cronos: tiempo), 2) lenguaje de acción, no simboliza sino que hace, la acción actúa como comunicación, 3) la sobrevivencia está basada en la mendicidad: pequeños robos (no tienen otra salida) y 4) consiguen alivio por drogas (especialmente pegamentos). Vemos que para las condiciones de fuga extrema son cuatro soluciones correctas, terribles pero inevitables: acronicidad, para evitar la angustia de la muerte, porque no hay historia, por lo tanto no hay conciencia de finitud; lenguaje de acción, no hubo aprendizaje de la simbolización; violencia transgresora, el débil no sobrevive en la calle, y droga para no psicotizarse.

Es así como se trata de explicar desde la psiquis anacrónica que permite entenderse como una conciencia fuera de tiempo, y que nos permita entender como los niños y adolescentes "gomeros", ven su realidad y de las carencias que le fueron impuestas como las figuras paternas, educación, enseñanzas y todos los vínculos que ellas conllevan y que le hubiesen permitido integrarse a la sociedad. Entonces no es ilógico definir que para los chicos de la calle su conciencia es acrónica, como tal su conocimiento se encuentra en un eterno 
presente en el que se debe solo subsistir sin ninguna visión de futuro o proyecto de vida, y eso conlleva que sus vínculos sean momentáneos, y que su conservación está dada por la capacidad de integrarse para aminorar la carga de supervivencia y de tener que satisfacer en algo sus necesidades elementales, las mismas que son distribuidas entre sus integrantes como lo muestra algunos elementos en el siguiente cuadro:

Cuadro núm. 1

\begin{tabular}{|c|c|c|c|c|c|c|}
\hline \multicolumn{7}{|c|}{ Funciones o roles que cumplen dentro del grupo } \\
\hline & $\begin{array}{l}\text { Consiguen } \\
\text { comida }\end{array}$ & $\begin{array}{l}\text { Compran o } \\
\text { consiguen } \\
\text { cemento }\end{array}$ & $\begin{array}{c}\text { Compran } \\
\text { guanchaca }\end{array}$ & $\begin{array}{l}\text { Protección } \\
\text { contra } \\
\text { extraños }\end{array}$ & $\begin{array}{l}\text { Se encargan de } \\
\text { las pertenencias } \\
\text { del grupo }\end{array}$ & $\begin{array}{l}\text { Sirven de } \\
\text { campanas } \\
\text { cuidan de } \\
\text { fundeados o } \\
\text { dormidos }\end{array}$ \\
\hline Niñas & $\mathrm{X}$ & $\mathrm{X}$ & & & $\mathrm{X}$ & $\mathrm{X}$ \\
\hline Niños & $\mathrm{X}$ & $\mathrm{X}$ & & & $\mathrm{X}$ & $\mathrm{X}$ \\
\hline $\begin{array}{l}\text { entre } 13- \\
16 \text { años }\end{array}$ & & $\mathrm{X}$ & $\mathrm{X}$ & & $\mathrm{X}$ & $\mathrm{X}$ \\
\hline $\begin{array}{l}\text { entre } 16- \\
18 \text { años }\end{array}$ & & & $\mathrm{X}$ & $\mathrm{X}$ & $\mathrm{X}$ & $\mathrm{X}$ \\
\hline
\end{tabular}

Elaborado por la autora. Fuente: entrevista niños y adolescentes de la calle.

\section{Universo de la Investigación}

Esta investigación tuvo como escenario el centro colonial de Quito, específicamente el parque el Ejido donde se localizan un grupo de adolescentes gomeros con los cuales se realizó esta investigación. Se trabajó con un grupo de 20 niños, niñas y adolescentes comprendidos entre 8 a 20 años de edad, con quienes se realizó conversaciones preliminares que permitieron, poco a poco, ganar su confianza pues, hay que decirlo, es difícil poder entablar una relación con este tipo de grupos por su propia naturaleza y el mismo historial de maltrato por el que han pasado. 
Cuadro no. 2

Distribución de la población de estudio

\begin{tabular}{|c|c|c|c|}
\hline EDADES & VARONES & MUJERES & TOTAL \\
\hline Entre 8-12 & 6 & 2 & 8 \\
\hline Entre 12-22 & 8 & 4 & 12 \\
\hline TOTAL & 14 & 6 & 20 \\
\hline
\end{tabular}

Elaborado por la autora. Fuente: entrevista niños y adolescentes de la calle.

\section{Análisis situacional del grupo}

Dentro del diagnóstico situacional podemos observar varios factores que nos ayudaron a focalizar el perfil sociológico de estos chicos:

- El grupo se encontraba formado por 20 niños y adolescentes de entre 8 y 20 años que habían permanecido en la calle un promedio de 7 años, siempre rondando el Centro Histórico. Cinco de ellos tenían hijos a pesar de su corta edad, dejándonos ver su nivel de precocidad y desinformación acerca de todo lo sexual; sin embargo, cabe recalcar que sus niños no se encontraban con ellos. Su ruta o trayecto es por lo general la Marín, la Plaza del Teatro, San Blas, el sector de los juzgados, La Alameda y la Caja del Seguro.

- Dormían habitualmente en el parque La Alameda frente a la Notaria 35 ubicada en la Avenida 10 de Agosto. En ese lugar se encontraban en la noche para pernoctar, acomodados en cartones y protegidos con viejas cobijas que guardan detrás de pequeños muros de cemento que se encuentran junto a los edificios de la avenida, siempre y cuando -como menciona uno de ellos- "diosito no haga que llueva". De pasar aquello, duermen detrás de la Caja del Seguro o en los rincones que les ofrecen las puertas enrollables de los almacenes cercanos. Su comida general- 
mente la obtienen de los restaurantes que se encuentran en el sector, la cual es repartida a todo el grupo, es decir, existen encargados de ir en busca de comida y, a diferencia de lo que podríamos pensar, regresan con ella para que el resto del grupo pueda alimentarse.

- Su fuente de trabajo es inestable o nula; por lo general se dedican a la venta de caramelos o a lavar carros en las esquinas. Como es obvio se encuentran expuestos a cualquier peligro de la calle: el abuso de grupos delincuenciales, prostitución, problemas de territorio con otros grupos de gomeros, así como el excesivo abuso policial.

- Una parte del grupo ha asistido a fundaciones que les ha permitido alejarse en algo de su adicción y que, por lo general, son los que trabajan ocasionalmente. Cuatro integrantes del grupo, dos chicas y dos hombres, son transitorios, es decir, no duermen con ellos, pero pasan todo el resto del tiempo ahí. Según lo que pudimos concluir de lo observado, ellos antes pertenececían al grupo de niños de la calle. Todos ellos continúan fundeándose y por lo menos la mitad ha experimentado con otras drogas como la marihuana, la coca, pastillas, etc., pero como son más costosas, siempre llegan a consumir cemento de contacto.

- A diferencia de muchos otros grupos que se encuentran en otros sectores de la ciudad, este grupo es uno de los que tiene integrantes más jóvenes por lo que deben cuidarse más, ya que grupos que han permanecido mucho más tiempo en la calle suelen atacarlos $\mathrm{y}$, por esto, se encuentran constantemente en peleas por sus pertenencias y por las que uno de los integrantes, al defender a su "familia", perdió la vida.

\section{Sociología del grupo de gomeros}

Se realizó un análisis de las entrevistas a partir de su transcripción. Se analizó la información de acuerdo con los tópicos más relevantes para comprender el tema de investigación, y así construir el perfil del sujeto. 
Cuadro no. 3

\subsubsection{Levantamiento de datos cualitativos}

\begin{tabular}{|c|c|c|}
\hline $\begin{array}{l}\text { Interés a } \\
\text { investigar }\end{array}$ & Metodología & Características \\
\hline $\begin{array}{l}\text { Factores de } \\
\text { riesgo }\end{array}$ & $\begin{array}{l}\text { Cualitativo- } \\
\text { etnográfico }\end{array}$ & $\begin{array}{l}\text { - } \quad \text { normalización de la venta ilegal } \\
\text { irresponsabilidad en la comercialización las expe- } \\
\text { riencias positivas del consumo } \\
\text { - } \\
\text { violencia policial } \\
\text { trabajo en las calles. }\end{array}$ \\
\hline $\begin{array}{l}\text { Antecedentes } \\
\text { padres }\end{array}$ & $\begin{array}{l}\text { Cualitativo- } \\
\text { historia de vida }\end{array}$ & $\begin{array}{l}\text { - alcohólicos, adictos a diferentes drogas, madres } \\
\text { prostitutas, mal tratantes } \\
\text { - muertos por sobredosis, presos, nunca lo conocieron. }\end{array}$ \\
\hline $\begin{array}{l}\text { Tipo de maltrato } \\
\text { intrafamiliar }\end{array}$ & $\begin{array}{l}\text { Cualitativo- } \\
\text { historia de vida }\end{array}$ & $\begin{array}{l}\text { FUGA, físico, psicológico (insultos, vejación, } \\
\text { abuso sexual } \\
\text { utilizados como objetos para venta de drogas. }\end{array}$ \\
\hline $\begin{array}{l}\text { Deserción } \\
\text { escolar }\end{array}$ & $\begin{array}{l}\text { Cualitativo- } \\
\text { historia de vida }\end{array}$ & $\begin{array}{l}\text { bajo rendimiento, exclusión escolar, problemas } \\
\text { conductuales (provocados por el ambiente y pro- } \\
\text { blemas en casa), tiempo para trabajar, desinterés, } \\
\text { ansiedad, tristeza, apatía, irritabilidad, ideación } \\
\text { suicida (provocados por el ambiente y problemas } \\
\text { en casa). }\end{array}$ \\
\hline $\begin{array}{l}\text { Motivaciones } \\
\text { hacia el } \\
\text { consumo. }\end{array}$ & $\begin{array}{l}\text { Cualitativo- } \\
\text { etnográfico }\end{array}$ & $\begin{array}{l}\text { - Curiosidad. Sobre todo en los niños. } \\
\text { - } \text { drogto. Son baratos en comparación con otras } \\
\text { Disponibilidad. Los consiguen de formas muy } \\
\text { fácil en cualquier en establecimientos comerciales } \\
\text { - De fácil manejo. Forma sencilla de administración } \\
\text { - Legalidad. La posesión de inhalables no se en- } \\
\text { cuentra tipificada en código penal por lo que re- } \\
\text { sulta más fácil su consumo y venta. }\end{array}$ \\
\hline $\begin{array}{l}\text { Cuando } \\
\text { consumen: }\end{array}$ & $\begin{array}{l}\text { Cualitativo- } \\
\text { etnográfico } \\
\text { entrevista semi } \\
\text { estructurada }\end{array}$ & $\begin{array}{l}\text { tristeza, depresión, policía los golpeaba, recuerdo } \\
\text { de casa, } \\
\text { compañeros separados del grupo diferentes razo- } \\
\text { nes (muerte, cárcel, fundaciones). }\end{array}$ \\
\hline
\end{tabular}




\begin{tabular}{|c|c|c|}
\hline $\begin{array}{l}\text { Interés a } \\
\text { investigar }\end{array}$ & Metodología & Características \\
\hline $\begin{array}{l}\text { Gratificaciones } \\
\text { de consumo }\end{array}$ & $\begin{array}{l}\text { Cualitativo- } \\
\text { etnográfico } \\
\text { Cualitativo- } \\
\text { entrevistas } \\
\text { focalizadas- } \\
\text { etnográficos }\end{array}$ & $\begin{array}{l}\text { Estrategias de subsistencia infantil en las calles: la } \\
\text { goma (alivia el hambre y el frio). } \\
\text { Evasión de situaciones desagradables (miedo a la } \\
\text { violencia policiaca, intentos de violación por el } \\
\text { otro o su mismo sexo, soledad, depresión). } \\
\text { - Identificación con el grupo. Alteración del estado } \\
\text { de ánimo. describen como placenteros los efectos } \\
\text { eufóricos como inhibidores }\end{array}$ \\
\hline $\begin{array}{l}\text { Qué inhalante } \\
\text { predomina: }\end{array}$ & $\begin{array}{l}\text { Cualitativo- } \\
\text { etnográfico }\end{array}$ & - Cemento, Tiñer. \\
\hline $\begin{array}{l}\text { Prácticas } \\
\text { sexuales: }\end{array}$ & $\begin{array}{c}\text { Cualitativo- } \\
\text { entrevistas } \\
\text { focalizadas- } \\
\text { Estudios de casos }\end{array}$ & $\begin{array}{l}\text { - Carecen de todo tipo de protección, embarazos no } \\
\text { planeados, abortos violentos, etc. }\end{array}$ \\
\hline $\begin{array}{l}\text { Como lo } \\
\text { consiguen }\end{array}$ & $\begin{array}{c}\text { Cualitativo- } \\
\text { etnográfico } \\
\text { Entrevistas cara } \\
\text { a cara } \\
\end{array}$ & $\begin{array}{l}\text { - Compran en la ferretería. Recurren a la mendici- } \\
\text { dad para conseguir dinero. }\end{array}$ \\
\hline Subempleos & $\begin{array}{l}\text { entrevista semi } \\
\text { estructurada }\end{array}$ & - Limpian carros. Venden caramelos. \\
\hline
\end{tabular}

Elaborado por la autora. Fuente: entrevista niños y adolescentes de la calle.

\section{Roles en las conductas en el grupo}

Los roles son cambiados, creados, combinados según la necesidad del sujeto. Por ejemplo, las mujeres adoptan el rol de varones por motivos de supervivencia y de seguridad. Los niños menores adoptan el rol de hijos de los individuos que mantienen el liderazgo, convirtiéndose en los que cuidan a los bebés, piden comida, piden dinero, piden ropa para todo el grupo. Los adolescentes mayores son los encargados de comprar los inhalantes, de buscar refugio y proteger a los más pequeños y a las mujeres, especialmente a las que se encuentran en estado de gestación, cambian habitualmente de pareja y tienen que conformarse con la voluntad e imposición de los líderes. El grupo líder, está formado por dos hasta cuatro chicos, son los que realizan conductas infractoras, los que defienden al grupo de la sociedad y de delincuentes comunes, por lo general son los más fuertes y los que han estado en la cárcel más de una vez. 
Cuadro no. 4

Origen territorial

\begin{tabular}{|c|c|c|c|}
\hline Muestra & 20 & Rural & Ciudad \\
\hline Niñas & 3 & 8 \\
\hline Niños & 7 & 10 \\
\hline TOTAL & 10 & 2 \\
\hline
\end{tabular}

Elaborado por la autora. Fuente: entrevista niños y adolescentes de la calle.

En el cuadro, podemos apreciar que de una muestra de 20 niños ubicados en el lugar de investigación 7 son niños y 3 niñas pertenecientes a la ciudad, mientras un total de 10 niños, divididos en 8 niños y 2 niñas, con tales resultados podemos concluir que el porcentaje de niños y adolescentes procedentes del sector rural y urbano es similar

\section{Cuadro no. 5}

\begin{tabular}{|c|c|c|c|}
\hline \multicolumn{4}{|c|}{ Niveles socioeconómicos } \\
\hline & Alto & medio & bajo \\
\hline niñas & 0 & 1 & 4 \\
\hline niños & & $2 \mathrm{t}$ & 13 \\
\hline TOTALES & 0 & 3 & 17 \\
\hline
\end{tabular}

Elaborado por la autora. Fuente: entrevista niños y adolescentes de la calle.

El gráfico muestra que el $85 \%$ de los niños y adolescentes "callejizados" vienen de un nivel bajo económicamente hablando comparado contra un 15\%, lo que deja ver que el limitante económico es una de las grandes causas para la callejización de la niñez y adolescencia en Quito. 
Cuadro no. 6

Edades de inicio delconsumo

\begin{tabular}{|c|c|c|c|}
\hline Muestra (20) & Entre 6-8 & Entre 9-11 & Entre 12 en adelante \\
\hline Niñas & 0 & 4 & 1 \\
\hline Niños & 8 & 0 & 7 \\
\hline TOTAL & 8 & 4 & 8 \\
\hline
\end{tabular}

Elaborado por la autora. Fuente: entrevista niños y adolescentes de la calle.

En edades de entre 6-8 años, el inicio del consumo de inhalantes, de una muestra de 20 sujetos, se da en mayor porcentaje en los niños más que las niñas, más concretamente en un $40 \%$, mientras que las niñas empiezan el consumo más o menos a una edad de entre 9-11 años de edad y en un $40 \%$ los niños y niñas en edades de 12 en adelante. Podemos así observar que los niños en relación con las niñas, están propensos de iniciarse a edades más tempranas en el consumo de inhalantes.

Cuadro no 7

Edades cuando deja de consumir

\begin{tabular}{|c|c|c|c|c|}
\hline Sexo & Entre 9-11 & Entre 12-14 & 15 en adelante & No lo ha dejado \\
\hline Niñas & 0 & 2 & 0 & 3 \\
\hline Niños & 0 & 2 & 1 & 12 \\
\hline
\end{tabular}

Elaborado por la autora. Fuente: entrevista niños y adolescentes de la calle.

El 75\% de los entrevistados, es decir, la gran mayoría no ha dejado de consumir inhalantes. Podemos concluir que ha medida que pasa el tiempo por distintos motivos, es más complicado alejarse del consumo de esta droga. 
Cuadro no. 8

Edad de inicio en las calles

\begin{tabular}{|c|c|c|c|}
\hline Sexo & Entre 6-8 & Entre 9-11 & Mas de12 \\
\hline Niñas & 2 & 3 & \\
\hline Niños & 7 & 1 & 7 \\
\hline
\end{tabular}

Como podemos observar el mayor porcentaje, el $45 \%$, de niños y niñas que se inician en las calles se encuentra ubicado entre los 6 y 8 años de edad, siendo los niños en su mayoría los que se inician a esta temprana edad.

Cuadro no. 9

Nivel de escolaridad

\begin{tabular}{|c|c|c|c|c|c|}
\hline Sexo & Ninguna & Básica $\left(1^{\circ} \mathrm{a} 7^{\circ}\right.$ & Básica $8^{\circ}-10^{\circ}$ & $\begin{array}{c}\text { Bachillerato } \\
1^{\circ}-3^{\circ}\end{array}$ & $\begin{array}{c}\text { Superior } \\
\text { universidad, } \\
\text { institutos) }\end{array}$ \\
\hline Niñas & 1 & 4 & & & \\
\hline Niños & 6 & 9 & & & \\
\hline
\end{tabular}

Elaborado por la autora. Fuente: entrevista niños y adolescentes de la calle.

El 65\% de los niños, niñas y adolescentes solo han estudiado hasta la básica media, siendo los niños el grupo mayoritario, mientras que, el $35 \%$ no cuenta con ninguna formación académica.

Cuadro no. 10

Frecuencia de consumo

\begin{tabular}{|c|c|c|c|c|c|c|}
\hline $\begin{array}{c}\text { Frecuencia de } \\
\text { consumo }\end{array}$ & Diario & $\begin{array}{c}\text { Cada 2 } \\
\text { días }\end{array}$ & $\begin{array}{c}\text { Cada } \\
3 \text { días }\end{array}$ & $\begin{array}{c}\text { Cada } \\
\text { 4 días }\end{array}$ & $\begin{array}{c}\text { Cada } \\
\text { semana }\end{array}$ & Observaciones \\
\hline niñas & 2 & 0 & 2 & & 1 &. \\
\hline niños & 6 & 4 & 3 & 2 & & \\
\hline
\end{tabular}

Elaborado por la autora. Fuente: entrevista niños y adolescentes de la calle. 
Observaciones: Procuran proteger a las adolescentes embarazadas evitando que su frecuencia de consumo sea poco o ninguno.

El consumo diario, tanto en niños como en niñas, es similar en porcentaje a pesar de que el consumo en niñas cada tres dias tienen igual peso, el consumo cada dos dias y cuatro es minimo, concluyendo que las niñas dejan pasar por lo general un cierto periodo de tiempo para volver a consumir, en cambio que este mismo consumo en los niños es diario.

\section{Análisis del perfil sociológico}

Edades comprendidas:

Techo alto: 18 años

Techo bajo: 6 años

Número de la población, aproximado:

"El centro histórico de Quito y el sur de la ciudad son las áreas en donde se registra mayor cantidad de niños callejizados. De acuerdo a las cifras del $\mathrm{Mu}-$ nicipio, de los 2.228 niños, niñas y adolescentes contabilizados, un 33,1\% está en el centro, mientras el 25,4\% se encuentran en la zona de la Administración Eloy Alfaro, ubicada en el sur de la ciudad, y el 10,5\% también está en el sur, en espacios no definidos". ${ }^{4}$

Sexo: masculino: $80 \%$ Femenino: $20 \%$.

Donde viven: parques, plazoletas, calles más transitadas y pernoctan en parques portales de edificios, iglesias, casa abandonadas donde se establece su territorio (del grupo).

Trabajo: no existe actividad laboral estable, se dedican al comercio esporádico, pedir dinero y comida, conocer instituciones de beneficencia donde se abastecen de comida, ropa y productos que pueden ser vendidos, pero que en su mayoría servirá para el consumo de la solución o cemento de contacto.

4 "El País: 33,1\% de niños callejizados están en el centro histórico de Quito", en: Diario El Universo del lunes 28 de abril del 2008. 


\section{Sociabilidad del grupo}

Existen ciertos comportamientos y actitudes que no pueden ser descifrados a través de cuestionarios y entrevistas, por lo tanto utilizamos el método de la observación para especificar este conjunto de conductas que se traducen en códigos y normas empleadas por ellos. De lo que pudimos observar citamos a continuación:

El grupo se convierte en la familia de cada individuo, son tan solidarios que a pesar de haber recibido agresiones de un miembro del grupo no dudan en ayudarle, protegerle y brindarle acogida a esta persona. Es una práctica habitual el que individuos mayores aconsejen positivamente a menores.

Frente a la sociedad el individuo no traicionará ni dejará solo a otro miembro del grupo.

I: ¿Qué te pasó en la cara gato?

$\mathrm{E}$ : Me pegaron los negros, pero mis panas me ayudaron, querían quitarnos las cobijas.

E2 Sí, ahora ya les correteamos, ya no les dejamos que nos peguen.

I: ¿Qué pasó, qué hay con lo de la chompa cuéntanos?

E: Vendimos una chompa en 25 dólares, y nos toca repartirnos pero el gato no estaba ayer, pero sí te guardamos, tranquilo.

Aunque no existe una jerarquía establecida, existe un respeto intrínseco por el grupo líder, por las adolescentes con pareja las que están en estado de gestación, por los más pequeños y los bebés.

I: ¿Cuándo están así, drogados no aprovechan para llevarse las cosas de los demás?

E: NO.....cómo nos vamos a robar entre nosotros mismos, entre nosotros no.

I: ¿Loco, dónde está la novia del gato ahora?

E: La man estaba embarazada, ya no tiene que fundear, tiene que cuidar al chamito.

Cuidan en grupo a los más pequeños a menos de encontrarse bajo los efectos de droga, en tal caso se crean conflictos en el grupo. Cuidan de los enfermos y heridos.

Todos estos valores están sujetos al grado de afectación por la droga y a la empatía que un miembro del grupo sienta por el resto en un específico momento. 
I: ¿Qué te pasa, por qué necesitas de los demás para vender?

E: Porque yo soy cieguito, me dieron un machetazo en la cabeza y ya no veo casi nada apenas sombras, ellos me ayudan a vender mis caramelos.

No existen vínculos del individuo con su familia, ya que por lo general es el "factor de fuga hacia la calle". Los vínculos con la comunidad no existen o son muy débiles, ya que hay gran desconfianza porque la considera maltratante y de quien reciben marginación. Dentro del grupo los vínculos creados dependen de la necesidad del individuo, no llegando a convertirse en vínculos emocionales o sociales, al ser niños, niñas y adolescentes sin patrones familiares ni sociales a seguir, su emocionalidad es polarizada, compulsiva y determinada por las relaciones de comunidad propias del grupo.

\section{Desescolarización}

Según los datos levantados en el cuadro no. 9 y los gráficos no. 10 y 11, nos muestran el nivel de escolaridad de los niños y adolescentes antes de que se insertaran en las calles, teniendo que solo el $65 \%$ del grupo, estudió hasta la básica media (1ro a $7 \mathrm{mo}$ año). Un niño y adolescente gomero callejizado tiene como característica la total desescolarización, pues es más probable que "niños de la calle", utilizando el termino dado por la UNICEF, para determinar a niños que se encuentran en la calle, pero que regresar a sus hogares, tengan escolarización justamente por el mismo motivo que sus vínculos familiares no se han roto del todo y entonces la familia se convierte en ese nexo entre el escenario escolar y niño o adolescente y aun así existe un porcentaje del $35 \%$ de niños y adolecentes que a pesar de estar con sus familias jamás fue a una escuela, evidenciando así, otro tipo de violencia cometido en su contra pues les es negado el derecho del conocimiento, el mismo que podría mejorar sus condiciones de vida.

Más aún, el porcentaje de niños que han ido a la escuela pero que empiezan a sufrir violencias de todo tipo en casa, no han logrado interiorizar normas que les permita una nueva fase de socialización y entonces, por lo general, son estos niños los que darán problemas conductuales y que lastimosamente al no ser entendidos sus antecedentes por parte de autoridades y docentes son violentados imponiendo sin adaptación previa una disciplina equivocada. Pero cuando el niño empieza a romper esos vínculos familiares, las violencias que han recibido en casa se trasladan también a la escuela y "el niño se convierte en víctima y 
victimario de nuevas violencias" (Sánchez Parga, 2009), finalmente rompiendo también esos lazos escolares, que si lo vemos de forma consciente y autocritica, es la única salida que tendría para poder surgir.

\section{Conductas infractoras}

Todos los chicos del grupo realizan el consumo de inhalantes como una forma de subsistencia. La mayoría de individuos del grupo no son delincuentes, llegan a hurtar artículos para su alimentación y de primera necesidad. Por lo general, el grupo líder se arriesga a cometer infracciones de hurto, robo, escándalos en la vía pública. Los mismos individuos del grupo no se consideran una pandilla ya que ellos conocen la estructura jerárquica y de posesión que una pandilla tiene.

\section{Lenguaje callejero}

\begin{tabular}{|c|c|c|}
\hline Goma $=$ cemento de contacto & $\begin{array}{l}\text { El personal = grupo que vive } \\
\text { con ellos }\end{array}$ & Guanchaca $=$ licor \\
\hline Buches de funda = inhalación & $\begin{array}{l}\text { Fundear }=\text { inhalar cemento } \\
\text { de contacto }\end{array}$ & Jama $=$ comida \\
\hline Camello $=$ trabajo & Fierro $=$ cuchillo & Trueno $=$ pistola \\
\hline $\begin{array}{l}\text { Mota, mafufa, hierba= } \\
\text { marihuana }\end{array}$ & Gorilas, milicos $=$ militares & $\begin{array}{l}\text { Tomba, chapas, perros } \\
=\text { policia }\end{array}$ \\
\hline Muerte blanca $=$ sobredosis & Chamito $=$ niño pequeño & Mansito $=$ un hombre \\
\hline Vacilan $=$ están juntos & La corre, cana $=$ correccional & Dar el vire $=$ matar \\
\hline
\end{tabular}

\section{Obtención y consumo de inhalantes}

Al no existir ningún cuerpo legal que prohíba el expendio de sustancias toxicas e inhalantes, las consiguen de las ferreterías como cualquier ciudadano común.

I: ¿Haber, por ejemplo, cómo consiguen el cemento?

E: En la ferretería, vamos y le pedimos que nos venda un dólar de cemento y nos vende. 
I: ¿Y les vende así nada más?

E: Sí.

Dadas las características de los inhalantes podemos entender que es de fácil acceso y uso para quienes han hecho de este vicio su forma de vida. Conocer cuáles son los inhalantes que permiten llegar a un estado de "no hambre" o "no frío" solo es cuestión de tiempo, de permanencia en las calles. Los principales puntos de expendio de inhalantes, principalmente de cemento de contacto o pega de tubo, es cualquier ferretería o tienda de materiales de construcción, lo que nos lleva a pensar que cualquier persona, incluso cualquier niño, puede llegar a estos y convertirse en un comprador y consumidor, puesto que su costo no es elevado, en comparación con otras drogas.

La manera más general y por la que deriva de su nombre es la inhalación, que se la realiza al poner el contenido (cemento de contacto) en una funda plástica para que sea de mas fácil uso y fingimiento para los demás, pues esta se introduce dentro de la vestimenta (sacos chompas, abrigos, etc.), de tal forma que al inclinar la cabeza se logre la inhalación, también lo suelen realizar desde el mismo tarro de pegamento. Otra manera de consumirlo es mezclarla con algún colorante que le dé buen olor, como fresco solo, sobre todo a quienes están iniciándose en el consumo. La pega de tubo es una de las drogas más fuertes por su contenido químico (thf, ciclohexanona-disolvente) y mortal, por lo que su consumo está restringido únicamente para quienes han sobrepasado, si podemos decirlo de alguna manera, los efectos del cemento de contacto y que, posiblemente, sean los que tienen su salud mas descompuesta que los demás, suelen usarla mezclada con el cemento de contacto por su olor fuerte y su larga duración, su costo es más elevado.

\section{Testimonios de niños y niñas gomeros}

Hemos recogido testimonios que son los que realmente nos darán una luz para poder discernir los códigos de convivencia de los chicos "gomeros" callejizados. 


\section{FAUSTO MURILLO (Juanito) 14 años}

FACTORES DE FUGA: muerte del padre por sobredosis de alcohol, muerte de la madre en accidente de tránsito y ausencia de familiares que mantengan la tutela.

Mi papá y mamá se murieron en un accidente y nadie me quiso ayudar así que estuve caminando por las calles hasta que me cogió la noche y unos panas me dieron un lugar donde dormir, debajo del puente del terminal y luego nos fuimos a una casa vieja, hasta que nos sacaron los policías y nos llevaron a la corre, ahí nos bañaron en agua helada, nos hicieron "teque" y después nos mandaron. Y ahora yo ya sé vivir en cualquier lugar que me coja la noche, cojo mis cartones me pego unos "buches" de funda y duermo.

Mi hermano Juan también vive en la calle aunque está un poco loco de tanta funda.

Mi papa, y mis hermanos mayores pasan solo tomando en la calle de las papas fritas, de la Marín, del centro y ya no les interesa para nada lo que nos pase. Yo quiero que me ayuden ya que estoy cansado de la calle.

\section{VERÓNICA ESPINOZA (19 años)}

FACTORES DE FUGA: alcoholismo sufrido por parte de los padres y alto nivel de agresión sexual por parte del padre.

Yo me salí de mi casa porque mi papá cuando estaba borracho quería abusar de mí y yo le tenía mucho miedo, y a mi mamá no le podía decir ya que ella no me cree, y me pegaba. Aquí en la calle aprendí a fundear, a robar, hasta que le conocí al mono con el que tengo un hijo. Ahora ya no fundeo pero quiero salir de la calle ya que mi hijo mucho se enferma es posible que ya arriende un cuarto, y trabaje vendiendo galletas o algo de mercadería. Quiero salir de la calle, ya que me he ganado por defender a la "Pillajo" un corte en la cara, con el filo de la botella que cogió la Vero. Ayúdeme a salir ya que me estoy dañando más. Si yo tengo un cuarto le prometo que ya no me salgo aunque mi mamá y mi papá ya no crean en mí. 


\section{ALEXANDRA (La Pillajo) 19 años}

FACTORES DE FUGA: ausencia del padre, empobrecimiento económico de alto grado.

Yo tengo 2 hijos ahora del gusano; yo vivo en la calle ya que mi papá nos dejo abandonando con mi mama cuando tenía 8 años; no sé por qué lo hizo, he vivido en la calle mucho tiempo, he visto cosas muy feas, aprendí a fundear por mis amigos; con ellos compraba un tarro o dos pero ya dejé por mis hijos, ellas cuando nacieron tuvieron algún problema y él médico me dijo que fue por el vicio. Ya voy a arrendar un cuarto y vivir para mis hijas para que no sigan este camino, voy a vender caramelos yo si puedo salir adelante ya lo verá aunque sola ya que el gusano dice que va a cambiar pero solo ofrece. Si puede ayúdeme a estudiar ya que yo si sé, cuando estaba con los salesianos era buena estudiante, pero cuando estuve embarazada me mandaron y ahí quedó todo, yo quería seguir belleza ayúdeme, yo sí puedo.

\section{DAVID ALVAREZ (17 años)}

FACTORES DE FUGA: alcoholismo sufrido por parte de los padres y violencia física y psicológica intrafamiliar.

Yo salí a las calles ya que mis papás se separaron, no sé por qué, creo que por que mi papá tenía otra mujer y se pasaban solo peleando y chupando. Mi hermano que me ayudaba y aconsejaba se fue a España y me dejaron con una tía que me pegaba mucho. Así que un día cogí una parada de ropa y me fui a vivir en la calle, mis papás ni se acuerdan de mí y ya no me interesa, ellos "vacilan" sus casas y sus nuevos hijos, aquí vivo bien ya que mis amigos me apoyan, me ayudan, me aconsejan, yo voy a tener un hijo con la Miriam y ahí voy a dejar la calle, ya que no quiero que mi hijo sufra lo mismo que yo, sobre todo cuando los policías nos pegan y nos llevan a la cárcel. Le prometo que sí voy a cambiar. Mire las señales que tengo por estar en la calle, me han dado palo sin miedo para que no me peguen les he dicho que soy "enfermito" y me he hecho el desmayado y ahí me han dejado", hay un "mansito" que me quiere matar por eso yo ando con un cuchillo para defenderme. Cuando peleo cojo dos piedras en la mano para pelear con más fuerza y golpear más duro. 


\section{Causas de callejización de niños, niñas}

\section{Condición familiar}

La mayoría de estos niños han sido expuestos a violencia intrafamiliar y vienen de familias frágiles localizadas en comunidades o barrios, donde se han agrupado familias de pocos recursos económicos y con alto índice de problemas sociales (delincuencia, prostitución, alcoholismo, drogadicción y otros).

Cuadro no. 12

\begin{tabular}{|c|c|c|c|c|c|c|c|}
\hline \multicolumn{7}{|c|}{ Situación geográfica familiar } \\
\hline $\begin{array}{c}\text { Ubicación } \\
\text { familiar } \\
\text { (barrios) }\end{array}$ & Toctiuco & La libertad & El Panecilo & $\begin{array}{c}\text { La } \\
\text { Colmena }\end{array}$ & $\begin{array}{c}\text { La } \\
\text { ferroviaria }\end{array}$ & $\begin{array}{c}\text { San } \\
\text { Roque }\end{array}$ & TOTAL \\
\hline Niñas/ & 3 & & & & & 2 & 5 \\
\hline Niños & 4 & 3 & 2 & 2 & 1 & 3 & 15 \\
\hline TOTAL & 7 & 3 & 2 & 2 & 1 & 5 & 20 \\
\hline
\end{tabular}

Elaborado por: Karina Cabrera C. Fuente: entrevista niños y adolescentes de la calle.

\section{Violencia Intrafamiliar}

La familia es la primera institución social, es aquí donde nacen los vínculos que fortalecerán a un niño, niña o adolescente. Si estos se rompen, la violencia provocada repercutirá en la niñez y adolescencia con mucha más crueldad que cualquier otra. Las relaciones familiares forman una parte vital en la manera en la que se desarrolla un niño. Este tipo de violencia es considerada un factor clave para impulsar a los niños a las calles.

I: ¿Por qué saliste a la calle?

E: (Gato) Porque mi papá me golpeaba mucho, y yo ya no aguantaba; entonces me fui, luego quise regresar, pero él ya tenía otra mujer.

I: ¿Por qué saliste a la calle? 
E: (Angélica) Mire yo me salí de la casa ya que mi papá toma mucho y cuando esta chumado es muy bravo, quiere pelear con todos, a mi mama le pega, le manda sacando ya que dice que es su casa, solo porque es de la mamá, de mi abuela; ella también es mala, nos manda sacando ya que le defiende a mi papá. Él no trabaja, quiere que nosotros le demos de comer, por eso salimos a pedir cartones y botellas para tener plata. A mi hermana la Paola casi la mata solo porque regó el trago. Le iba a dar con un fierro; si no es por el payaso, mi pareja, que le alcanzó a quitar el fierro le hubiera dado, y después nos mando sacando del cuarto que nos dio mi tía diciendo que somos malcriados, que no le dejamos pegar a mi hermana que tiene solo 10 años.

\section{Violencia educativa}

- Los niños de la calle comúnmente son expulsados de sus escuelas como resultado de peleas, reacciones agresivas hacia sus maestros, por tratar con violencia a otros niños o por pertenecer a familias incapaces de pagar las cuotas escolares, comprar uniformes o materiales escolares. El uso del castigo corporal en la escuela, humilla a los niños mientras refuerza la aceptación de una cultura de violencia. A pesar de que las metodologías y la no vulneración de derechos ha avanzado mucho en nuestro país, la escuela todavía sigue manteniendo rezagos de exclusión a niños y adolescentes con problemas sociales (alcohol, drogas, violencia familiar, etc.), y no logra establecerse un currículo que permita la inclusión de todos estos casos con un seguimiento adecuado de los debidos departamentos que permita salvaguardar al estudiante y no convertirse también en uno más de los factores expulsores hacia la callejización.

I: ¿Por qué estas en la calle?

E: Porque me escape de la escuela, me trataban mal, porque no entendia

\section{Violencia sexual}

Una gran parte de ellos han sufrido abuso sexual, por parte de sus propios familiares (padres, tíos, primos, vecinos, etc.). El trauma causado por este acontecimiento y la falta de un adulto que les permita tener una ayuda apropiada 
para salir psicológicamente de este sufrimiento, les lleva a huir de casa y establecerse en un lugar que para ellos es más seguro.

I: ¿Qué pasó, por qué estás en la calle?

E: (Verónica) Yo me salí de mi casa porque mi papá, cuando estaba borracho, quería abusar de mí y yo le tenía mucho miedo, y a mi mamá no le podía decir, ya que ella no me cree y me pegaba. Aqui en la calle aprendí a fundear, a robar,...

\section{Cuadro no. 13}

Víctimas de violencia sexual

\begin{tabular}{|c|c|c|c|}
\hline & Entre 6-8 & Entre 9-11 & 12 en adelante \\
\hline niñas & 1 & 1 & 1 \\
\hline niños & 2 & 2 & 4 \\
\hline adolescentes & & & 3 \\
\hline
\end{tabular}

Elaborado por: Karina Cabrera C. Fuente: entrevista niños y adolescentes de la calle.

\section{Situación Económica}

La precaria situación económica de las familias de estos niños y adolescentes es una de los principales factores de callejización, pues al no apoyar con el dinero suficiente para ayudar a sus casas, sufren maltrato intrafamiliar (son golpeados física y sicológicamente). Esto los convierte también en niños trabajadores, pasando inmediatamente por un proceso de callejización y si no existe ayuda les llevará a convertirse posiblemente en un niño, niña o adolescente gomero.

I: ¿Lolita por qué saliste de tu casa?

E: Porque mi mamá me pegaba mucho, porque como no le llevaba mucho dinero de la venta y mejor me sali a los trece. 


\section{Conclusiones}

- Los niños, niñas y adolescentes "gomeros" se encuentran comprendidos entre la edad de 6 a 18 años que hacen de la calle su hogar, a falta de uno propio o muchas ocasiones de uno nunca conocido, ahí encuentran una familia, y satisfacen sus necesidades básicas, logrando sobrevivir en medio de su difícil aprendizaje.

- Su factor expulsor definitivamente es la familia. La violencia en su más alta expresión, esta dentro de la familia justamente por el vínculo tan estrecho y los sentimientos involucrados. La violencia dada dentro de la familia es consecuencia de las características de mercado del sistema económico actual. Las violencias más frecuentes para esta expulsión es la violencia física, sexual y psicológica.

- Su nivel académico es incompleto o nulo, ya que la mayoría de ellos sufrieron una exclusión por parte de la escuela, y los que decidieron abandonarla por que no encontraban ningún vínculo que les permitiera continuar.

- Al encontrarse ya en las calles su característica académica es la desescolarización, pues su nexo con el escenario educativo era su familia.

- Sobrevivir en la calle ha despertado en ellos destrezas para conseguirlo, como astucia y fuerza física, como medios para encajar en un mundo peligroso y como parte de su ser social.

- La pobreza extrema que va sufriendo el grupo requiere de estrategias sumamente fuertes para subsistir. Por la falta de obtención de necesidades básica, las drogas entran en su mundo y por necesidades económicas el consumo se va delimitando a drogas más baratas pero mucho más mortales como el tiñer, gasolina, cemento de contacto, pvc (pega de tubo), también el ser humano (niños y adolescentes) van llegando al fondo de toda la descomposición social, es decir, llegan al lugar más profundo de toda la pobreza, a una marginalidad completamente invisible.

- Los trabajos esporádicos que realizan son generalmente de vendedores de caramelos en buses, plazas, espectáculos públicos, semáforos, también trabajan cuidando carros o haciendo malabares en semáforos de la ciudad. A pesar de su dura sobrevivencia, muchos de ellos muestran notoriamente su condición infantil: juegan, disfrutan, aprenden, y socializan.

- La inhalación de cemento de contacto no es exclusivamente por adicción, es una de las tantas formas de sobrevivir. En el ámbito sexual, la falta de 
educación e información acerca del tema hace que la promiscuidad y los embarazos precoces, así como enfermedades de transmisión sexual, sean algo común entre ellos, siendo la misma droga que los lleva a un estado de excitación mayor cuando han consumido, un atenuante para este problema, inclusive han sufrido de abuso sexual.

- Se ha "adulterado" a estos niños, niñas y adolescentes, ignorando completamente su condición infantil. Todos cumplen un rol o una función específica, que a pesar de no ser estática, saben que tienen que cumplirla, pues de ello depende la alimentación, vestido, cobija y vicio de los demás. El más fuerte de ellos o el que ha estado preso es el que defiende al grupo de otros grupos que les quieran hacer daño, pero no consideran que exista un líder en sí.

- $\quad$ Las mujeres son protegidas, en lo que cabe, por su condición de embarazo o cuando ellos consideran que no tienen edad suficiente para realizar ciertas tareas. Los más pequeños son los que se encargan por lo general de conseguir comida y cobijo, así como de estar pendientes de su cuidado. A las mujeres o a los adolescentes también se les encarga la venta de objetos que a veces han sido robados a falta de conseguir dinero en sus trabajos habituales. Esta función la realiza este grupo ya que son de los que menos sospecha tiene la policía o los que no tienen antecedentes penales. El dinero de esto es repartido entre los miembros que delinquieron, los cuales lo utilizan en la mayoría de veces para comprar comida para todos o conseguir cemento para fundear.

- Dentro de su círculo o familia, como ellos le llaman, a pesar de lo inimaginable, se han fomentado ciertos valores que les permiten tener identidad dentro del grupo como son la lealtad, la honestidad, solidaridad, respeto. Su conservación está dada por la capacidad de integrarse para aminorar la carga de supervivencia y de tener que satisfacer de alguna forma sus necesidades elementales.

\section{Bibliografía}

DA SILVA, F. Forselledo, A.

1993 Clasificación Geopolitica-Estructural de las Sustancias Psicoactiva, Boletín FORO Año 6. No. 16. Montevideo: IIN/OEA-OPTAR. 
ENGBERINK Gerard Oude y Dirk Kruijt

1996 Niños de la calle en Europa. San José, Costa Rica: Facultad Latinoamericana de Ciencias Sociales (FLACSO), Cuaderno de Ciencias Sociales 95.

FORSELLEDO, Ariel Gustavo

2002 Niñez en Situación de Calle Un Modelo de Prevención de las Farmacodependencias basado en los Derechos Humanos. Montevideo-Uruguay, Segunda Edición.

GUTIÉRREZ, Rafael y Leticia Vega

2010 Las Investigaciones Psicosociales De La Subsistencia Infantil En Las Calles Desarrolladas En El INP Durante Los Últimos 25 Años, Salud Mental, No 006, México.

MEDINA-MORA, María Elena

2002 Metodología para la elaboración de estudios a nivel nacional y local y estudios para grupos especiales relacionados con adicciones. México.

MOFFATT, Alfredo

2011 Antropología de los chicos de la calle. Sociopatología: El psiquismo acrónico publicado.

http://www.facebook.com/notes/alfredo-moffatt/antropolog\%C3\%ADade-los-chicos-de-la-calle-sociopatolog $\% \mathrm{C} 3 \% \mathrm{ADa}-\mathrm{el}-\mathrm{psiquismo-}$ acr\%C3\%B3nico-alfr/203909582964394html.

SÁNCHEZ PARGA, José

2009 Sociología infantil. Maestría en política social para la promoción de infancia y adolescencia. Quito- Ecuador: UPS.

2010 Antropología de las violencias. Maestría en política social para la promoción de infancia y adolescencia. Quito-Ecuador: UPS.

RUANO, Marco

1996 “Atención preventiva en las calles", Proyecto salesiano chicos de la calle, CICADOEA, Cuaderno de trabajo inédito. Quito: Organismo especializado de la OEA programa de promoción integral de los derechos del niño.

SAURI SUÁREZ, Gerardo, Moisés Vidales y José Saucedo

1991 El concepto de niño callejero. México: Educación con el niño callejero (EDNICA).

TORRES, Hugo

2008 Introducción a las teorías sociales. Modulo para maestría en política social para la promoción de infancia y adolescencia. Quito: UPS.

WALDMAN, G.

1980 "La situación del niño en la familia contemporánea” en: Revista del menor y la familia, Año 1, Vol. 1. México DF: Sistema Nacional para el Desarrollo Integral de la Familia (DIF). 